\title{
THE ONSET OF TWINNING IN METALS: A CONSTITUTIVE DESCRIPTION
}

\author{
M. A. MEYERS ${ }^{1} \dagger$, O. VÖHRINGER ${ }^{2}$ and V. A. LUBARDA ${ }^{1}$ \\ ${ }^{1}$ Department of Mechanical and Aerospace Engineering, University of California, San Diego, La Jolla, CA \\ 92093-0411, USA and ${ }^{2}$ Institute for Materials Research I, University of Karlsruhe (TH), 76128 Karlsruhe, \\ Germany
}

( Received 13 August 1999; received in revised form 21 July 2001; accepted 21 July 2001)

\begin{abstract}
A constitutive approach is developed that predicts the critical stress for twinning as a function of external (temperature, strain rate) and internal (grain size, stacking-fault energy) parameters. Plastic deformation by slip and twinning are considered as competitive mechanisms. The twinning stress is equated to the slip stress based on the plastic flow by thermally assisted movement of dislocations over obstacles, which leads to successful prediction of the slip-twinning transition. The model is applied to body centered cubic, face centered cubic, and hexagonal metals and alloys: $\mathrm{Fe}, \mathrm{Cu}$, brasses, and $\mathrm{Ti}$, respectively. A constitutive expression for the twinning stress in BCC metals is developed using dislocation emission from a source and the formation of pile-ups, as rate-controlling mechanism. Employing an Eshelby-type analysis, the critical size of twin nucleus and twinning stress are correlated to the twin-boundary energy, which is directly related to the stacking-fault energy (SFE) for FCC metals. The effects of grain size and SFE are examined and the results indicate that the grain-scale pile-ups are not the source of the stress concentrations giving rise to twinning in FCC metals. The constitutive description of the slip-twinning transition are incorporated into the Weertman-Ashby deformation mechanism maps, thereby enabling the introduction of a twinning domain. This is illustrated for titanium with a grain size of $100 \mu \mathrm{m}$. (C) 2001 Acta Materialia Inc. Published by Elsevier Science Ltd. All rights reserved.
\end{abstract}

Keywords: Twinning; Metals; Constitutive equations

\section{INTRODUCTION}

The response of metals and ceramics to mechanical stresses can produce the following structural changes: slip (by dislocation motion); twinning (which also requires dislocation activity); phase transformations; and fracture [1]. Slip and fracture have received the greatest amount of attention from both theoretical and experimental researchers during the past 60 years. Mechanical twinning and displacive (martensitic) transformations also constitute a significant modes of deformation and can dominate under specific deformation conditions. Whereas dislocation motion is highly sensitive to strain rate and temperature (e.g. Becker [2] and Seeger [3-5]), twinning has a much lower sensitivity to these parameters. Nevertheless, it is well known that dislocation activity is intimately connected with twinning nucleation and growth. A comprehensive review of mechanical twinning has

$\dagger$ To whom all correspondence should be addressed. Tel.: +1-858-534-4719; fax: +1-858-534-5698. Meyers)

E-mail address: mameyers@mae.ucsd.edu (M. A been recently provided by Christian and Mahajan [6], in addition to several other overview treatments [712]. However, the classical deformation-mechanism maps, also called Weertman-Ashby maps [13, 14], do not have a twinning domain. This is most likely due to the absence of well-tested constitutive equations. Mechanical twinning can have two effects on the evolution of plastic deformation:

1. It subdivides the grains and therefore increases the barriers to slip, and the work-hardening rate. This has been demonstrated by Mulford and Kocks [15], and successfully modeled by Asgari et al. [16], El-Danaf et al. [17], Kalidindi [18, 19], Staroselsky and Anand [20] and Karaman et al. [21].

2. It contributes to plastic deformation due to twinning shear, which induces a decrease in the work hardening rate. This has been found in copper alloys by Vöhringer [22].

There has been in recent years a considerable effort devoted to the development of constitutive equations describing plastic deformation of metals and based on the fundamental aspects of dislocation motion, 
impeded by a variety of barriers. Cottrell [23] and Seeger [24] made important early contributions. Ono [25], Vöhringer [26], and Kocks et al. [27] varied the barrier shape and configuration to arrive at very satisfactory descriptions of the constitutive response. These ideas were incorporated into equations used in large-scale computational codes; prominent representatives are the Zerilli-Armstrong [28, 29] and the MTS [30] constitutive equations. A notable effort toward the incorporation of mechanical twinning into constitutive models was made in the constitutive equation developed by Armstrong and Worthington [31]. The computational and experimental studies by Zerilli and Armstrong [32] show that twinning can play a significant role. Karaman et al. [21] developed a constitutive equation for the combined slip/twinning deformation in Hadfield (FCC) steel; Tomé et al. [33] extended this to HCP metals. The research effort whose results are presented in this paper had as a primary objective the application of a constitutive description for the onset of twinning in conjunction with a constitutive equation for slip to obtain maps for the two regions (slip and twinning) for a variety of FCC, BCC, and HCP metals. A second objective was to use the constitutive description to obtain a linkage between fundamental nucleation parameters, grain size, and stacking-fault energy (SFE).

\section{THE TWINNING STRESS}

There are excellent overviews, such as one by Christian and Mahajan [6], on the effects of internal (material) and external parameters on the twinning stress. Four of these aspects, relevant to the constitutive description implemented here, are discussed next. The critical event in twinning is, for most cases, nucleation. Growth can occur at stresses that are a fraction of the nucleating stress $[8,26]$. It has been known for a long time that the local stress required to nucleate twinning is considerably higher than the homogeneous stress resulting from the external tractions. The possibility of homogeneous nucleation of twins in near perfect HCP crystals was reported by Bell and Cahn [34] and Price [35]. Their results, however, can also be interpreted as twinning being normally initiated by some defect configuration, because of the requirement of much higher stress for the homogeneous nucleation. A number of nucleation and growth mechanisms have been proposed and their description transcends the scope of this paper. Nucleation mechanisms for FCC metals were suggested by Suzuki and Barrett [36], Haasen and King [37], Miura et al. [38], Cohen and Weertman [39], Venables [40, 41], Sleeswik [42], Mahajan and Chin [43], Bolling and Richman [44], and others. For BCC metals, Cottrell and Bilby [45], Sleeswyk [46], and Hirth [47] proposed new or modified some of the existing mechanisms. An interesting alternative to the above mechanisms, all based on dislocation reactions, is the proposal by Orowan [48] that twins nucleate homogeneously.

\subsection{Effect of temperature and strain rate}

Figure 1 shows a compilation of twinning stress vs temperature for a number of metals (both mono and polycrystals). The striking aspect is that there seems to be a critical stress that is temperature insensitive. This issue has been debated in the literature, and there are diverging results. Bell and Cahn [34] observed a large scatter in single crystals. This could, however, be attributed to stress concentration sites other than pile-ups (surface notches, internal flaws, etc.). Hence, a distribution of twinning stresses, similar to a Weibull distribution for ceramic strength, could be expected. There are also reports of gradual decrease in the twinning stress with increasing temperature for FCC metals, by Bolling and Richman [44], and Koester and Speidel [49]. Christian and Mahajan [6] discuss this topic in detail. Mahajan and Williams [10] suggested that BCC metals have a negative dependence of twinning stress on temperature, while FCC metals have a slightly positive temperature sensitivity. However, Reed-Hill [50], based on the work on BCC $\mathrm{Fe}_{3} \mathrm{Be}$ by Bolling and Richman [44], concluded that whenever the deformation proceeds primarily by twinning, the flow stress tends to have a positive temperature dependence and a negative strainrate dependence. Venables [41] analyzed critically the existing data for FCC crystals and concluded that it was insufficient to reach a definitive conclusion. For the purposes of the subsequent calculations, it will be assumed that there is a critical stress for twinning that is either temperature independent or has a very low temperature dependence. For the FCC and HCP structures, the strain-rate dependence of the twinning stress has not received the same degree of attention. The only account in which the strain rate is varied over a very broad range is to the authors' knowledge the work of Harding [51, 52] on monocrystalline iron, shown in Fig. 1. The twinning shear stress at $10^{3} \mathrm{~s}^{-1}$ is ca $220 \mathrm{MPa}$, whereas it is about $170 \mathrm{MPa}$ at $10^{-3}$ $\mathrm{s}^{-1}$. This result is used in a simple constitutive equation for twinning presented in Section 3, but additional experiments are clearly necessary to establish the full strain-rate dependence.

Figure 2(a) shows the results by Chichili et al. [53] which illustrate eloquently the effect of stress on twinning. Twinning is an evolving process, increasing with stress, beyond its critical value. The results plotted in Fig. 2(a) were obtained at varying temperatures (77 and $300 \mathrm{~K})$ and strain rates $\left(10^{-3}\right.$ to $\left.10^{3} \mathrm{~s}^{-1}\right)$. Nevertheless, all the data fit into a single curve, showing that the number of twins/grain is a function of stress, independently of temperature and strain rate. Figure 2(b) shows similar results for an FCC alloy $(35 \% \mathrm{Ni}-35 \% \mathrm{Co}-20 \% \mathrm{Cr}-10 \% \mathrm{Mo})$ [16]. The fractional amount of twinning increases monotonically with stress. The fact that increasingly higher stresses are required to produce increasing amounts of twin- 


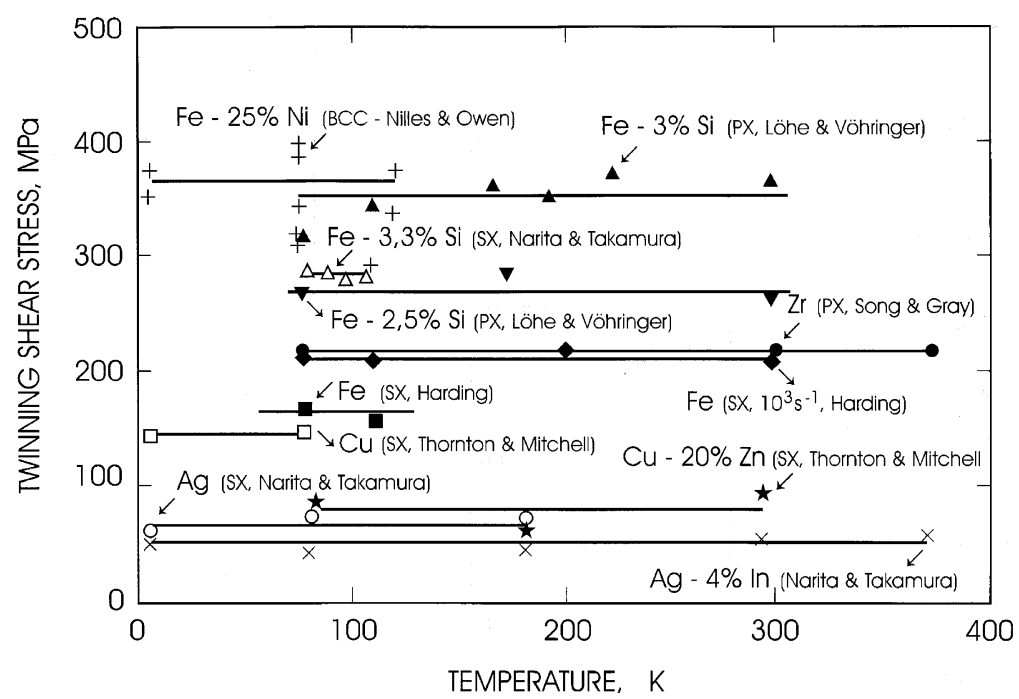

Fig. 1. Twinning stress as a function of temperature for a number of metals (both mono and polycrystals).
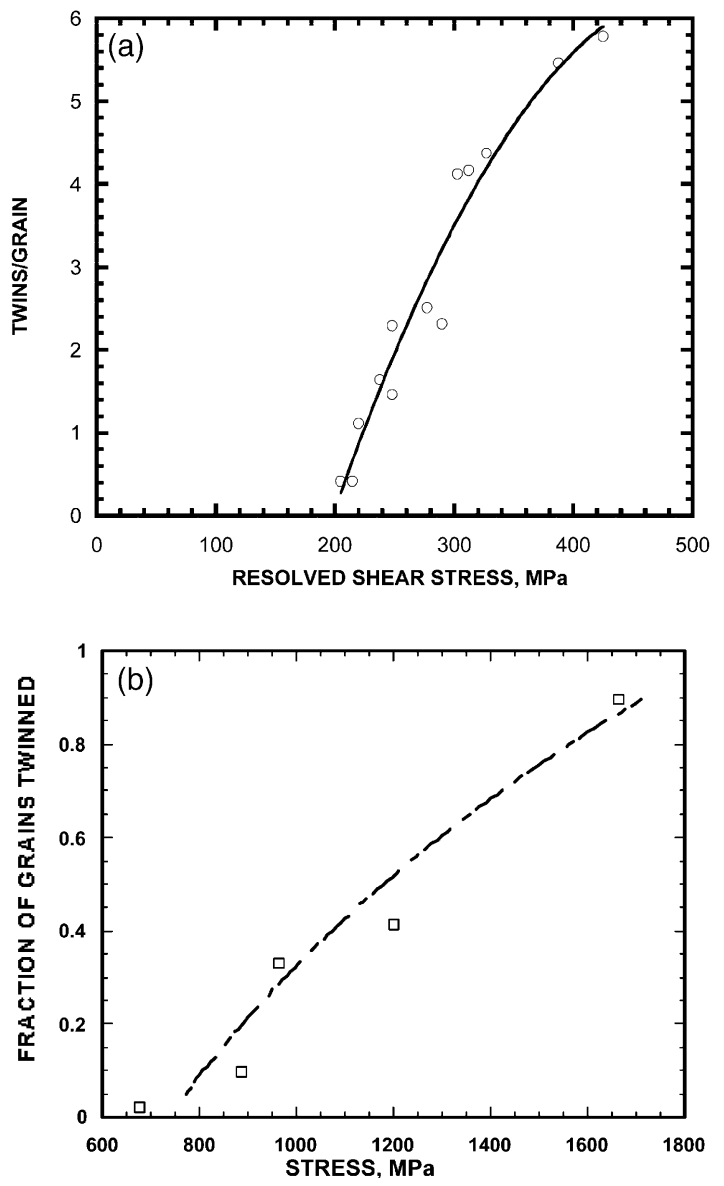

Fig. 2. Effect of stress on twinning: (a) twin density (measured in twins/grain) as a function of shear stress for $\mathrm{CP}$ titanium tested at $77,300 \mathrm{~K}$, and strain rates of $10^{-3}$ and $10^{3} \mathrm{~s}^{-1}$ (from Chichili et al. [53]). (b) Fraction of grains twinned as a function of stress for a $35 \% \mathrm{Ni}-35 \% \mathrm{Co}-20 \% \mathrm{Cr}-10 \% \mathrm{Mo}$ (FCC) alloy (from Asgari et al. [16]). ning can be qualitatively explained by the unloading (and associated shielding) occurring in the surrounding of a twinned region. This local unloading might or might not manifest itself by global stress drops in the stress-strain curve.

\subsection{Effect of grain size}

Another highly unique characteristic of twinning, first pointed out by Armstrong and Worthington [31], is the larger grain size dependence of the twinning stress, as compared with the slip stress. For most cases, a Hall-Petch relationship is obeyed, but with a slope $k_{\mathrm{T}}$, that is higher than the slope $k_{\mathrm{S}}$ for slip, that is:

$$
\sigma_{\mathrm{T}}=\sigma_{\mathrm{T} 0}+k_{\mathrm{T}} d^{-1 / 2}
$$

For example, the Hall-Petch slope for twinning in copper was found by Vöhringer [54] to be $k_{\mathrm{T}} \approx 0.7 \mathrm{MN} / \mathrm{m}^{3 / 2}$, which significantly exceeds the one for slip $k_{\mathrm{S}} \approx 0.35 \mathrm{MN} / \mathrm{m}^{3 / 2}$. Recent evidence by Song and Gray [57] suggests that the Hall-Petch slope for twinning in zirconium $\left(k_{\mathrm{T}} \approx 2.4 \mathrm{MN} / \mathrm{m}^{3 / 2}\right)$ is almost ten times the one for $\operatorname{slip}\left(k_{\mathrm{T}} \approx 0.25 \mathrm{MN} / \mathrm{m}^{3 / 2}\right)$. Table 1 is a compilation of data for BCC, FCC, and HCP metals from a number of sources [54-63]. The reason for the difference is not fully understood, but Armstrong and Worthington [31] suggest that twinning is associated with microplasticity, that is, dislocation activity occurring before the onset of generalized plastic deformation, whereas the yield stress is associated with generalized plastic deformation. It is very plausible that microplasticity and overall deformation are controlled by different mechanisms, that is, elastic anisotropy, incompatibility stresses, and barriers to slip. Recent results by El-Danaf et al. [17] reconfirm the significant effect of grain size on the propensity 
Table 1. Comparison of Hall-Petch slopes for slip and twinning

\begin{tabular}{|c|c|c|}
\hline Material & $\begin{array}{l}\mathrm{H}-\mathrm{P} \text { slope for } \\
\text { slip } k_{\mathrm{S}}(\mathrm{MPa} \\
\left.\mathrm{mm}^{1 / 2}\right)\end{array}$ & $\begin{array}{l}\mathrm{H}-\mathrm{P} \text { slope } \\
\text { for } \\
\text { twinning } \\
k_{\mathrm{T}}(\mathrm{MPa} \\
\left.\mathrm{mm}^{1 / 2}\right)\end{array}$ \\
\hline \multicolumn{3}{|l|}{$B C C$} \\
\hline $\mathrm{Fe}-3 \mathrm{wt} \% \mathrm{Si}$ (Hull) & $\begin{array}{l}10.4(\mathrm{RT}) \\
17.64(77 \mathrm{~K})\end{array}$ & 38.48 \\
\hline $\mathrm{Fe}-3$ wt\%Si (Loehe and Vöhringer) & 12 & 100 \\
\hline ArmcoFe (Loehe and Vöhringer) & 20 & 124 \\
\hline Armco Fe (Moiseev and Trefilov) & & 90 \\
\hline $\begin{array}{l}\text { Steels: 1010, 1020, } 1035 \text { (Loehe and } \\
\text { Vöhringer) }\end{array}$ & 20 & 124 \\
\hline $\begin{array}{l}\mathrm{Fe}-25 \mathrm{at} \% \mathrm{Ni}(\mathrm{BCC}) \text { (Nilles and } \\
\text { Owen) }\end{array}$ & 33 & 100 \\
\hline Cr (Marcinskowski and Lipsitt) & 10.08 & 67.75 \\
\hline Va (Lindley and Smallman) & $3.46(20 \mathrm{~K})$ & 22.37 \\
\hline \multicolumn{3}{|l|}{$F C C$} \\
\hline $\mathrm{Cu}$ (Vöhringer) & & $\begin{array}{l}21.6(77 \\
\mathrm{K})\end{array}$ \\
\hline $\begin{array}{l}\text { (Meyers et al.) } \\
\text { (Zerilli and Armstrong) }\end{array}$ & $\begin{array}{l}5.4(\mathrm{RT}) \\
5.2(\mathrm{RT})\end{array}$ & \\
\hline $\mathrm{Cu}-6 \mathrm{wt} \% \mathrm{Sn}$ & 7.1 & $\begin{array}{l}11.8(77 \\
\mathrm{K})\end{array}$ \\
\hline $\mathrm{Cu}-9 \mathrm{wt} \% \mathrm{Sn}$ & 8.2 & $\begin{array}{l}7.9(295 \\
\mathrm{K})\end{array}$ \\
\hline $\mathrm{Cu}-10 \mathrm{wt} \% \mathrm{Zn}$ & 7.1 & $\begin{array}{l}15.7(77 \\
\mathrm{K})\end{array}$ \\
\hline $\begin{array}{l}\mathrm{Cu}-15 \mathrm{wt} \% \mathrm{Zn} \text { (Vöhringer; Koester } \\
\text { and Speidel) }\end{array}$ & 8.4 & $\begin{array}{l}11.8(77 \\
\text { K) } \\
16.7(295 \\
\text { K) }\end{array}$ \\
\hline \multicolumn{3}{|l|}{$H C P$} \\
\hline $\mathrm{Zr}$ (Song and Gray) & 8.25 & 79.2 \\
\hline Ti (Okazaki and Conrad) & $6(78 \mathrm{~K})$ & $18(4 \mathrm{~K})$ \\
\hline
\end{tabular}

for twinning. A 70/30 brass with a grain size of 250 $\mu \mathrm{m}$ shows a much greater twinning density than with grain sizes of 9 and $30 \mu \mathrm{m}$. A $35 \% \mathrm{Ni}-35 \% \mathrm{Co}-$ $20 \% \mathrm{Cr}-10 \%$ Mo alloy which twins readily at a grain size of $40 \mu \mathrm{m}$, shows no evidence of twinning at a grain size of $1 \mu \mathrm{m}$. Similar effects were observed by Romhanji et al. [64] and Lahaie et al. [65]. Meyers et al. [66] performed shock compression experiments on copper at $35 \mathrm{GPa}$ and obtained profuse twinning for grain sizes of 117 and $315 \mu \mathrm{m}$, but virtually no twinning for a grain size of $9 \mu \mathrm{m}$.

\subsection{Effect of stacking-fault energy}

Suzuki and Barrett [36] and Venables [40, 41] proposed relationships between the SFE $\gamma_{\mathrm{SF}}$ and the twinning stress $\tau_{\mathrm{T}}$. It is well known that the twinning stress increases with increasing SFE. This is true mostly for FCC metals, and the classic plot by Venables $[40,41]$ shows this effect very clearly. Narita et al. [67] have shown that:

$$
\left(\tau_{\mathrm{T}}\right)_{\mathrm{Cu}}>\left(\tau_{\mathrm{T}}\right)_{\mathrm{Ag}}>\left(\tau_{\mathrm{T}}\right)_{\mathrm{Au}},
$$

in accordance with

$$
\left(\gamma_{\mathrm{SF}}\right)_{\mathrm{Cu}}>\left(\gamma_{\mathrm{SF}}\right)_{\mathrm{Ag}}>\left(\gamma_{\mathrm{SF}}\right)_{\mathrm{Au}} .
$$

Based on the analysis of $\mathrm{Ni}-\mathrm{Ge}$ alloys, $\mathrm{Cu}, \mathrm{Au}$, and
Ag, Narita and Takamura [11] found that $\gamma_{\mathrm{SF}}$ and $\tau_{\mathrm{T}}$ are proportional, such that $\gamma_{\mathrm{SF}}=2 b_{s} \tau_{\mathrm{T}}$, where $b_{s}$ is the Burgers vector for a Shockley partial. The strong decrease in the twinning stress, observed when Mo is alloyed with $\mathrm{Rh}$, has also been attributed to a SFE decrease [62]. Figure 3 shows a compilation of results by Venables [40] and Vöhringer [68]. The twinning stress for a number of copper alloys is shown to vary with the square root of the SFE. This effect is critically discussed in Section 5, where a new relationship is proposed.

\subsection{Effect of texture}

Gray et al. [63] have shown that texture has especially important effect on twinning in low-symmetry metals. They demonstrated this for $\mathrm{Ti}$ and $\mathrm{Zr}$. There is an intrinsic difference between slip and twinning that leads to significant differences in mechanical response when texture is present. A dislocation moves in opposite sense along the same direction when the applied stress is reversed, while the critical resolved shear stress (CRSS) is independent of the sense of dislocation motion. A twin, on the other hand, has a definite sense along which it shears. In the absence of texture these differences do not manifest themselves. The twinning and slip stresses are the same for either compressive or tensile applied tractions. In the presence of texture, however, the twinning stresses in compression and tension are different. The analysis presented in this paper applies to untextured polycrystalline aggregates only.

\subsection{Effect of stress state}

The simulations by Serra and Bacon [69] and Serra et al. [70] predict an increase in the lattice spacing between the twin plane and adjacent planes, with the

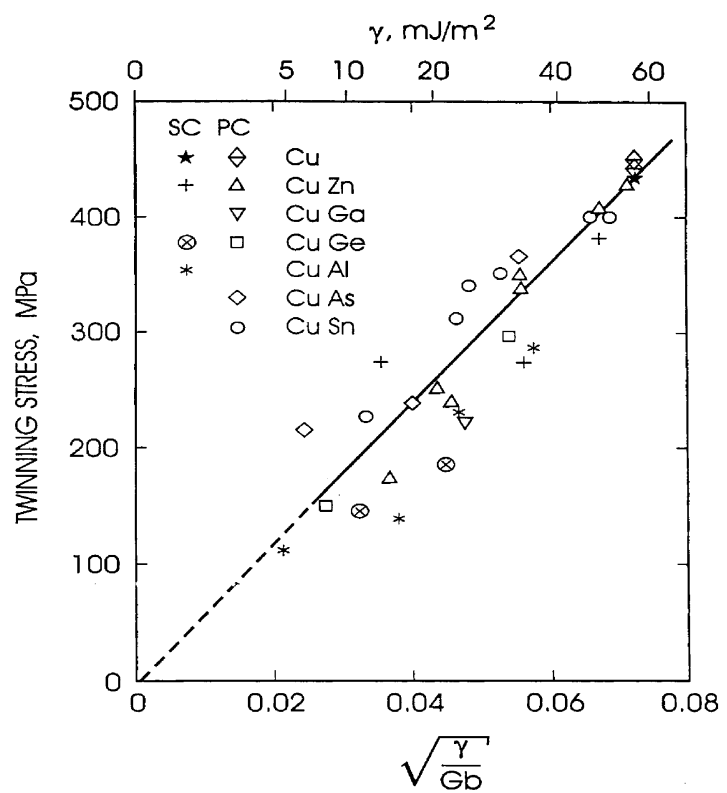

Fig. 3. Twinning (normal) stress as a function of stacking-fault energy for copper and copper solid solutions. 
dilatation of ca 0.004. Lebensohn and Tomé [71] discuss the effect of stress state on the critical stress for twinning and point out that this strain can affect the stress dependence. A normal stress affects the critical twinning stress, which can be included in the constitutive analysis. In martensitic transformations, when the product phase has a lower density than the parent phase, the effect is quite pronounced [72,73]. However, since there is no intrinsic difference in density between the twinned and untwinned regions, the effect is most probably of second-order for twinning. Consequently, it will not be incorporated in the computations presented herein.

\section{AN ANALYTICAL DESCRIPTION OF THE TWINNING STRESS}

In general, the tendency for the occurrence of mechanical twinning in BCC and HCP metals [7476] is quite strong at high strain rates and low temperatures, because the flow stress can be effectively raised up to the level required for twin formation. This is a direct result of their high strain-rate and thermal sensitivity. In BCC metals, twinning usually occurs prior to macro-yielding, and in many cases it is inhibited by significant plastic deformation. In FCC metals, which have a much lower strain-rate sensitivity, but higher work hardening ability, twinning often occurs after significant plastic deformation, which raises the corresponding stress level.

A simple constitutive twinning model for $\mathrm{BCC}$ metals is developed below, in which it is assumed that pile-ups play a key role in creating the stress concentration for the initiation; generalized dislocation activity seems to inhibit pile-up formation. It is based on the stress concentration generated by a pile-up due to activation of the Frank-Read or Köhler [77] source. A dislocation pile-up is created by a dislocation source, as shown in Fig. 4(a). The number of dislocations piled up is determined by the distance $l$ between the source and barrier, and the applied stress. The local stress in front of the barrier is equal to the product of the applied stress and the number of piledup dislocations. If a unique threshold twinning stress exists, the macroscopically measured twinning stress (or applied stress) will strongly depend on the microstructure of the sample, because the distance $l$ is microstructure-dependent. The initiation and propagation of the twin in a neighboring grain are shown in Fig. 4(b). The velocity of dislocations traveling from the source to the barrier is given by JohnstonGilman equation [78]

$$
v=A_{0} \tau^{m} \exp \left(-\frac{Q}{R T}\right),
$$

where $\tau$ is the stress acting on the dislocation, $Q$ is the activation energy, $T$ is the temperature, and $A_{0}$ (a)

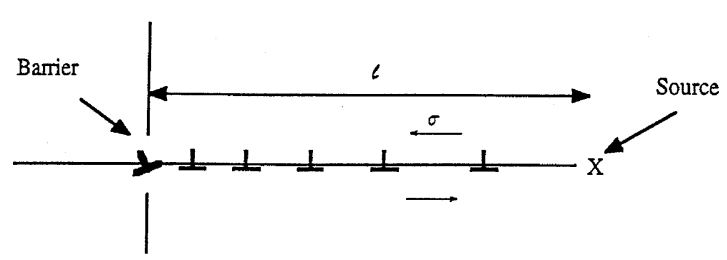

(b)

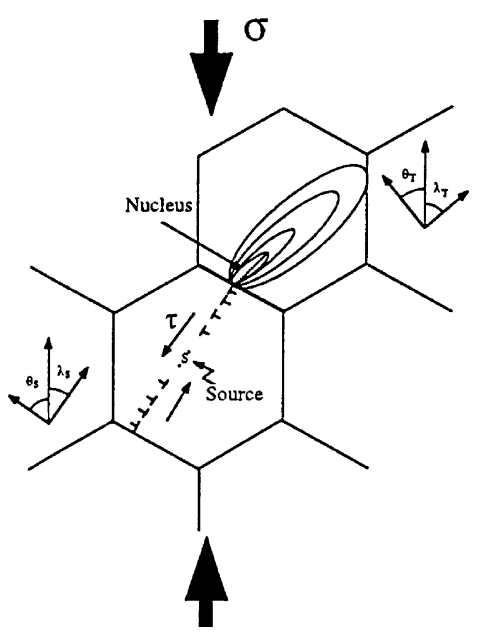

Fig. 4. (a) Schematics of edge dislocations piled up at a barrier. (b) Frank-Read or Köehler source creating a pile-up at grain boundary and twinning in neighboring grain.

and $m$ are constants. This equation applies to the lowvelocity regime, before viscous drag and relativistic effects come into play, and breaks down at temperatures close to $0 \mathrm{~K}$. The time for an individual dislocation to travel from source to barrier is $l / v$. Assuming, to a first approximation, that the time for all dislocations arriving at the pile-up and traveling from the source is the same and equal to $l / v$, the total time required to build up the dislocation pile-up of $n$ dislocations is equal to

$$
t=n \stackrel{l}{v} .
$$

This assumes that no two dislocations are simultaneously traveling to the barrier. Inserting equation (4) into equation (5) gives

$$
t=\frac{n l}{A \tau^{m}} \exp \left(\frac{Q}{R T}\right) .
$$

Since microslip occurs in the elastic stage, the relationship between stress and strain in a uniaxial loading configuration is $\sigma=E \epsilon$, so that under conditions of constant strain rate

$$
\sigma=E \dot{\epsilon} t
$$




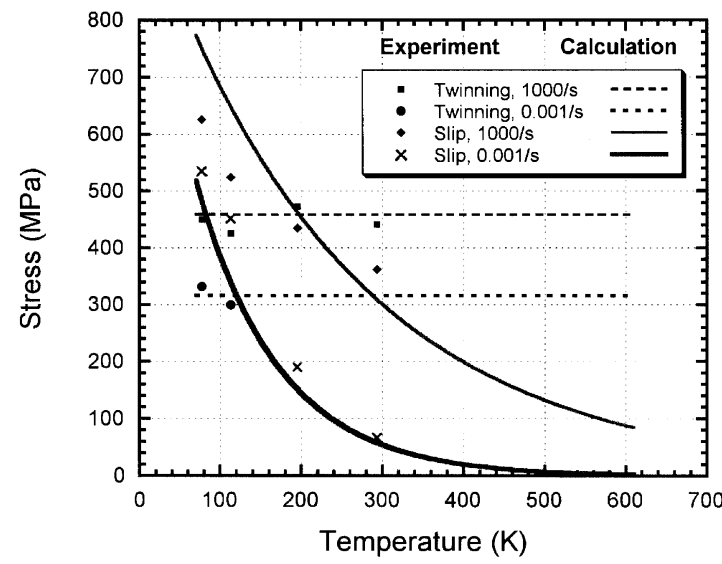

Fig. 5. Comparison between the computed and the experimental stresses for slip and twinning in single crystal iron (data from Harding [51, 52]).

Substituting equation (6) into equation (7) and using the relationship between the normal and shear stresses through the orientation factor $M_{\mathrm{T}}$, that is, $\sigma_{\mathrm{T}}=M_{\mathrm{T}} \tau_{\mathrm{T}}$, yields the twinning stress

$$
\begin{aligned}
& \sigma_{\mathrm{T}}=K \dot{\epsilon}^{1 / m+1} \exp \left[\frac{Q}{(m+1) R T}\right], \\
& K=M_{\mathrm{T}}\left(\frac{n l E}{M A_{0}}\right)^{1 / m+1} .
\end{aligned}
$$

This equation is applied to iron in order to establish the strain-rate and temperature dependence of twinning. The experimental results of Stein and Low [79] for $\mathrm{Fe}-3 \mathrm{wt} \% \mathrm{Si}$ are used for $m(=36)$ and $Q$ $(=51.66 \mathrm{~kJ} / \mathrm{mol})$. The activation energy was obtained by plotting the dislocation velocity (at constant stress) as a function of $1 / T$. The parameter $K$ is obtained by fitting equation (8) to experimental results reported for the twinning stress by Harding [51, 52]. The results are shown in Fig. 5 for both slip and twinning. The Zerilli-Armstrong equation for BCC metals was used for slip, that is

$$
\sigma_{\mathrm{S}}=\sigma_{\mathrm{G}}+C_{1} \exp \left[-\left(C_{3}-C_{4} \ln \frac{\dot{\epsilon}}{\dot{\epsilon}_{0}}\right) T\right]
$$

The parameters of Zerilli and Armstrong [28, 29] are listed in Table 2. The stress $\sigma_{\mathrm{G}}$ is the athermal

Table 2. Zerilli-Armstrong parameters for iron

\begin{tabular}{lc}
\hline \multicolumn{2}{c}{ Values } \\
\hline Zerilli-Armstrong parameters & 0 \\
$\sigma_{0 \mathrm{G}}$ & 1033 \\
$C_{1}(\mathrm{MPa})$ & 0.00698 \\
$C_{3}\left(\mathrm{~K}^{-1}\right)$ & 0.000415 \\
$C_{4}\left(\mathrm{~K}^{-1}\right)$ & \\
$T$ winning equation parameters & 380 \\
$K(\mathrm{MPa})$ & 36 \\
$m$ & 51.66 \\
$Q(\mathrm{~kJ})$ & \\
\hline
\end{tabular}

component of stress, and $\dot{\epsilon}_{0}$ is the reference rate of strain. It can be seen that the slip and twinning response differ drastically. Twinning exhibits a very weak temperature dependence. Below $20 \mathrm{~K}$, the Johnston-Gilman equation breaks down, because the stress goes to infinity. It is known that this is physically incorrect and an equation of Seeger's form, incorporating barriers of specific height and shape, would be preferable. An important conclusion that can be drawn from Fig. 5 is that the slip-twinning intersection is strongly dependent on strain rate, increasing from $120 \mathrm{~K}$ at $10^{-3} \mathrm{~s}^{-1}$ to $200 \mathrm{~K}$ at $10^{3}$ $\mathrm{s}^{-1}$.

\section{CONSTITUTIVE DESCRIPTION OF THE SLIP- TWINNING TRANSITION}

The rationale to be used in this section is that the onset of twinning occurs when the slip stress $\tau_{\mathrm{S}}$ becomes equal to the twinning stress $\tau_{\mathrm{T}}$, that is

$$
\tau_{\mathrm{S}}=\tau_{\mathrm{T}}
$$

It will be assumed that there is a CRSS for twinning that is independent of the stress state. For an untextured polycrystalline aggregate we then write

$$
\frac{\sigma_{\mathrm{S}}}{M_{\mathrm{S}}}=\frac{\sigma_{\mathrm{T}}}{M_{\mathrm{T}}}
$$

If the orientation factors $M_{\mathrm{S}}$ and $M_{\mathrm{T}}$ are assumed to be equal to each other, there follows

$$
\sigma_{\mathrm{S}}=\sigma_{\mathrm{T}}
$$

The described rationale will be applied to typical metals representative of the three crystalline systems of greatest importance for metals: $\mathrm{Fe}$ (BCC); $\mathrm{Cu}$ (FCC); and Ti (HCP). No attempt was made at the present stage to compare the calculated slip-twinning transitions with experimental results on the initiation.

\subsection{Iron $(B C C)$}

The constitutive equations (8) and (9) from Section 3 are used in equation (12), with the addition of the Hall-Petch terms for slip and twinning, $k_{\mathrm{S}}$ and $k_{\mathrm{T}}$, respectively. This leads to

$$
\begin{aligned}
& -\sigma_{\mathrm{G}}+K \dot{\boldsymbol{\epsilon}}^{1 / m+1} \exp \left[\frac{Q}{(m+1) R T}\right] \\
& -C_{1} \exp \left[-\left(C_{3}-C_{4} \ln \frac{\dot{\boldsymbol{\epsilon}}}{\dot{\epsilon}_{0}}\right) T\right]+\sigma_{\mathrm{T} 0}-\sigma_{\mathrm{S} 0} \\
& +\left(k_{\mathrm{T}}-k_{\mathrm{S}}\right) d^{-1 / 2}=0 .
\end{aligned}
$$

Figure 6(a) shows the slip and twinning curves for strain rates of $10^{-6}, 10^{-3}, 10^{0}, 10^{3}$ and $10^{6} \mathrm{~s}^{-1}$ for 
(a)

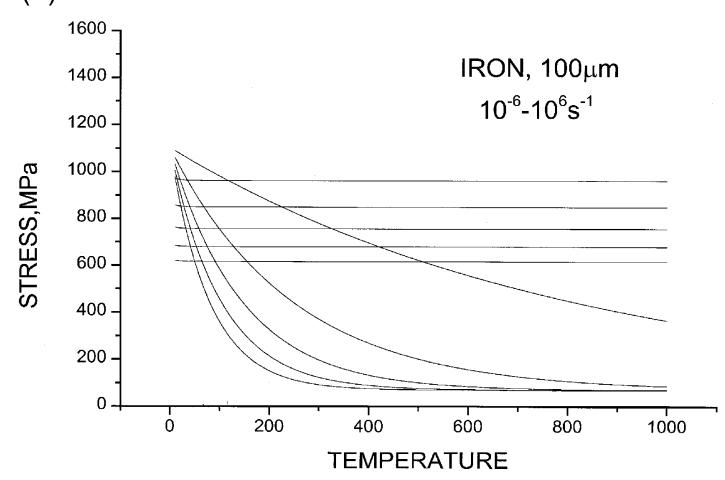

(b)

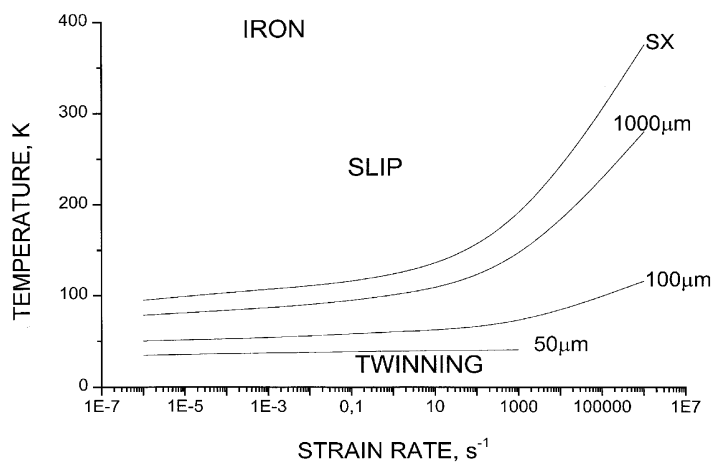

Fig. 6. (a) Calculated slip and twinning stresses for monocrystalline iron (grain size $d=100 \mu \mathrm{m}$ ) as a function of strain rate. (b) Calculated slip-twinning transition for iron of different grain sizes.

iron with a $100 \mu \mathrm{m}$ grain size. The intersections of these curves are given by the solution of equation (13). Figure 6(b) shows the slip-twinning transition for different grain sizes. The effect of grain size is clearly seen and is due to the fact that $k_{\mathrm{T}}>k_{\mathrm{S}}$. The values for $k_{\mathrm{T}}$ and $k_{\mathrm{S}}$ are given in Table 1 . The twinning domain for monocrystalline iron is much larger than for polycrystalline iron.

\subsection{Copper (FCC)}

It was not possible to apply the constitutive equation for twinning given in Section 3 to copper. Attempts were made at obtaining the activation energy and dislocation velocity exponent $m$ from Jassby and Vreeland [80], Greenman et al. [81], Kleintges and Haasen [82], and Suzuki and Ishi [83]. Jassby and Vreeland [80] only report dislocation velocities of $10 \mathrm{~cm} / \mathrm{s}$ and higher; this results in low values for $m$ and unacceptably high temperature and strainrate sensitivity for the twinning stress. Therefore, it was decided to simply use the twinning stress determined experimentally. Thornton and Mitchell [58] report a shear twinning stress for monocrystalline copper of $150 \mathrm{MPa}$ and this value is adopted. The Hall-Petch slope for twinning is given in Table 1 and was obtained by Vöhringer [54]; it is equal to 21.6
Table 3. Zerilli-Armstrong parameters for $\mathrm{Cu}$ and $\mathrm{Ti}$

\begin{tabular}{lll}
\hline Parameters & $\mathrm{Cu}$ & $\mathrm{Ti}$ \\
\hline$\sigma_{\mathrm{G}}(\mathrm{MPa})$ & 46.5 & 0 \\
$C_{1}$ & - & 990 \\
$C_{2}(\mathrm{MPa})$ & 890 & 700 \\
$C_{3}\left(\mathrm{~K}^{-1}\right)$ & $0.28 \times 10^{-3}$ & $1.06 \times 10^{-3}$ \\
$C_{4}\left(\mathrm{~K}^{-1}\right)$ & $1.15 \times 10^{-4}$ & $6.8 \times 10^{-4}$ \\
$C_{5}$ & - & - \\
$n$ & 0.5 & 0.5 \\
$k_{\mathrm{s}}\left(\mathrm{MPa} \mathrm{mm} \mathrm{mm}^{1 / 2}\right)$ & 5 & 6 \\
\hline
\end{tabular}

MPa $\mathrm{mm}^{1 / 2}$. The slip response was modeled by the Zerilli-Armstrong equation for FCC metals, with parameters given in Table 3. The resulting equation is

$$
\begin{aligned}
\sigma=\sigma_{\mathrm{G}}+C_{2} \exp \left[-\left(C_{3}-C_{4} \ln \frac{\dot{\epsilon}}{\dot{\epsilon}_{0}}\right) T\right] \\
+k_{\mathrm{S}} d^{-1 / 2}
\end{aligned}
$$

The constitutive responses are shown in Fig. 7, at two levels of plastic strain: 0.2 and 0.8 . It is seen that no twinning is obtained at 0.2 , but that at plastic strain of 0.8 the twinning occurs for all strain rates, for the grain size of $10 \mu \mathrm{m}$.

The slip-twinning transition as a function of grain size is shown in Fig. 8(a). This corresponds to plastic strain of 0.2. The effect of grain size is dramatic and influences the occurrence of twinning in a significant way. The effect of plastic strain is more clearly seen in the slip-twinning transition plot of Fig. 8(b). These calculations were made for a constant grain size of $10 \mu \mathrm{m}$. A plastic strain of 0.3 is necessary to initiate twinning. At ambient temperature, the strain rate of $5 \times 10^{3} \mathrm{~s}^{-1}$ and the strain of 0.8 are required to produce the twinning.

\subsection{Titanium $(H C P)$}

Zerilli and Armstrong $[84,85]$ demonstrated that the constitutive response of BCC metals can represent the behavior of titanium, with a few modifications to

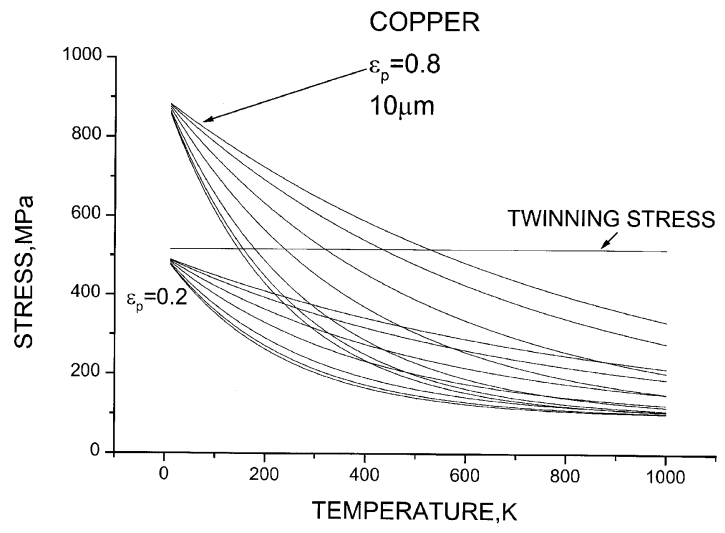

Fig. 7. Twinning and calculated slip stresses (at two levels of plastic strain) for $10 \mu \mathrm{m}$ grain size copper. 
(a)

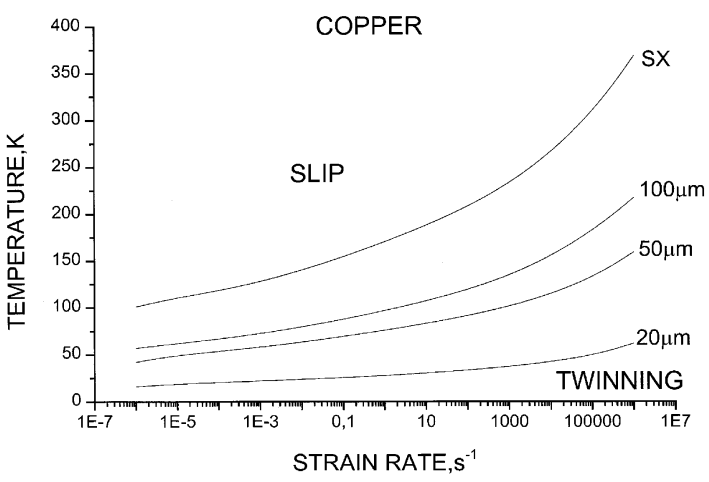

(b)

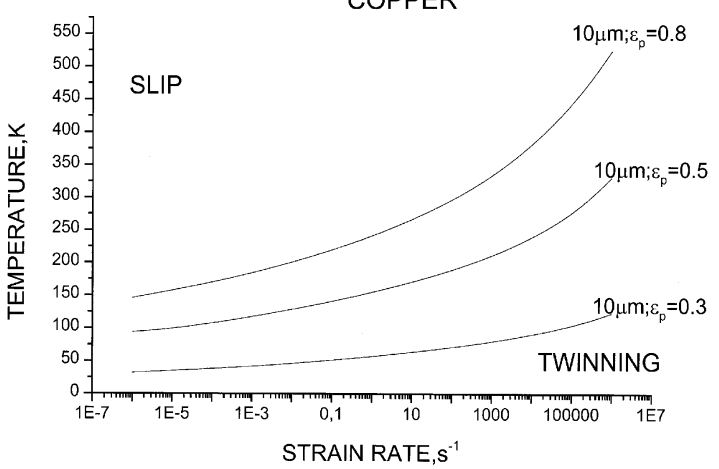

Fig. 8. (a) Calculated slip-twinning transition for copper of different grain sizes. (b) Calculated slip-twinning transition for copper $(d=10 \mu \mathrm{m})$, at different plastic strain levels: $0.3 ; 0.5$; and 0.8 .

incorporate the decrease in work hardening rate as the temperature is increased. The utilized equation is

$$
\sigma=\sigma_{\mathrm{G}}+C_{1}\left(\frac{\dot{\epsilon}}{\dot{\epsilon}_{0}}\right)^{C_{3} T}+C_{2} \epsilon^{n} \exp \left(C_{4} T\right)
$$

The term $\exp \left(C_{4} T\right)$ decreases the work hardening as $T$ increases. The twinning stress is represented by

$$
\sigma_{\mathrm{T}}=\sigma_{\mathrm{T} 0}+k_{\mathrm{T}} d^{-1 / 2} .
$$

Gray [86] reported a greater propensity for mechanical twinning of large grain sized $(240 \mu \mathrm{m})$ than smaller grain sized $(20 \mu \mathrm{m}) \mathrm{Ti}$ in dynamic testing, in agreement with the assumption that $k_{\mathrm{T}}>k_{\mathrm{S}}$. Conrad et al. [87] observed similar effects. The critical twinning stress is reported by Zerilli and Armstrong [84]. It is known that interstitials have a major effect on the mechanical response of $\mathrm{Ti}$ [87]. For instance, the yield stress of $\mathrm{Ti}$ at $\mathrm{RT}$ increases from 150 to 600 $\mathrm{MPa}$, when the oxygen equivalent $(\mathrm{O}+\mathrm{N}+\mathrm{C})$ percentage is increased from 0.1 to $1.0 \%$. This effect is more important than the grain size, since the yield stress increases from 450 to $600 \mathrm{MPa}$ when the grain size is decreased from $1.5 \mathrm{~mm}$ to $1.5 \mu \mathrm{m}$ (for $1 \% \mathrm{O}_{\text {eq. }}$ ). The Hall-Petch slope for slip was obtained by Okazaki and Conrad [88] and was found to be relatively insensitive to interstitial content. Conrad et al. [87] report twinning shear stresses in monocrystalline $\mathrm{Ti}$,

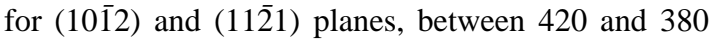
$\mathrm{MPa}$, respectively. These twinning stresses decrease with decreasing temperature. Taking a value of 800 MPa for the normal stress, the slip-twinning transition was estimated for grain sizes of 3,10 , and $100 \mu \mathrm{m}$. The results are shown in Fig. 9. It should be noted that the calculations were carried out for Marz titanium, with $0.1 \% \mathrm{O}_{\text {eq. }}$ and not with the material given by Zerilli and Armstrong [84], which has $\mathrm{O}_{e q .} \simeq 1 \%$ and a yield stress at ambient temperature and the strain rate $10^{-3} \mathrm{~s}^{-1}$ of $400 \mathrm{MPa}$. The interstitial content has a significant effect on the twinning stress, as discussed by Conrad et al. [87]. The rise in the twinning stress with interstitial content is more significant than the slip stress; this explains why the tendency for twinning decreases with interstitial increase. The effect of interstitials manifests itself in both the thermal and athermal components of the stress, and Conrad et al. [87] give a value of $\Delta \tau=0.02 G C_{\mathrm{i}}^{1 / 2}$ at $300 \mathrm{~K}$, where $\mathrm{C}_{\mathrm{i}}$ is the atomic concentration of interstitials, and $G$ is the shear modulus. This value can be used to modify the Zerilli-Armstrong equation (15) for HCP metals, such that

$$
\begin{aligned}
\sigma=\sigma_{\mathrm{G}} & +C_{1}\left(\frac{\dot{\epsilon}}{\dot{\epsilon}_{0}}\right)^{C_{3} T}+C_{2} \epsilon^{m} \exp \left(C_{4} T\right) \\
& +0.02 G C_{i}^{1 / 2}+k_{S} d^{-1 / 2}
\end{aligned}
$$

\section{EFFECT OF STACKING-FAULT ENERGY}

Figure 3 shows the significant effect of the SFE $\gamma_{\mathrm{SF}}$ on the twinning stress for FCC metals. As an illustration of the effect of SFE on the incidence of twinning, the $\mathrm{Cu}-\mathrm{Zn}$ system is analyzed. Gallagher [89] and Vöhringer [90] correlated the SFE to the electron/atom (e/a) ratio in copper alloys and arrived at the following expression

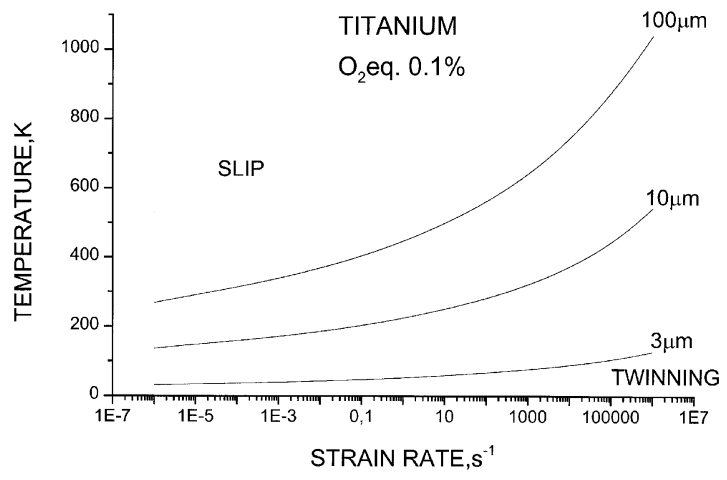

Fig. 9. Calculated slip-twinning transition for titanium of different grain sizes. 


$$
\ln \left(\frac{\gamma_{\mathrm{SF}}}{\gamma_{\mathrm{Cu}}}\right)=K_{1}\left(\frac{C}{C+C_{\mathrm{max}}}\right)^{2},
$$

where $\gamma_{\mathrm{Cu}}$ is the stacking fault energy for copper, and $C$ is the concentration of solute atoms. The maximum concentration of the solute is denoted by $C_{\max }$. The best fit was obtained with $K_{1}=12.5$ and $\gamma_{\mathrm{Cu}}=57 \pm 8 \mathrm{~mJ} / \mathrm{m}^{2}$. Equation (18) can be combined with the mathematical representation of data from Fig. 2, which is

$$
\sigma_{\mathrm{T}}=K_{2}\left(\frac{\gamma_{\mathrm{SF}}}{G b}\right)^{1 / 2}
$$

A good fit is obtained with $K_{2}=6 \mathrm{GPa}$. The same fit was satisfactorily obtained by Narita and Takamura [11] for Ni-Ge alloys. Substitution of equation (18) into equation (19) yields

$$
\sigma_{\mathrm{T}}=K_{2}\left(\frac{\gamma_{\mathrm{Cu}}}{G b}\right)^{1 / 2} \exp \left(K_{1}^{1 / 2} \frac{C}{C+C_{\mathrm{max}}}\right) .
$$

The effect of solid solution ( $\mathrm{Zn}, \mathrm{Ag}, \mathrm{Al}, \mathrm{Sn}, \mathrm{Ge}$ ) atoms on the mechanical response of $\mathrm{Cu}$ has been established quite carefully, as well as the effects of these solutes on the Hall-Petch relationship. Vöhringer [90] proposed the following expression for the yield stress

$$
\begin{gathered}
\sigma=\sigma_{\mathrm{G} 0}+K_{3} \epsilon_{\mathrm{L}}^{4 / 3} C^{2 / 3}+\left[\left(\sigma_{0}^{*}\right.\right. \\
\left.+K_{4} \epsilon_{\mathrm{L}}^{4 / 3} C^{2 / 3}\right)\left(\begin{array}{c}
\left.\left.1+\frac{k \ln \left(\dot{\epsilon} / \dot{\epsilon}_{0}\right)}{\Delta \Phi_{0}}\right)^{1 / p} T^{1 / p}\right]^{1 / q} \\
+k_{\mathrm{S}} d^{-1 / 2}
\end{array}\right.
\end{gathered}
$$

where $\sigma_{0}^{*}$ is the thermal and $\sigma_{\mathrm{G} 0}$ the athermal component of stress for pure copper, while $\Delta \Phi_{0}$ is the reference activation energy. Equation (21) is based on the overcoming of short-range obstacles that have the shape dictated by the parameters $p$ and $q$. The effect of solid solution atoms is manifested (both in the thermal and athermal components of stress) through the $C^{2 / 3}$ relationship and the Labusch parameter $\epsilon_{\mathrm{L}}$, which has different values for different solid solution atoms. $K_{3}$ and $K_{4}$ are parameters, and $\dot{\epsilon}_{0}$ is a reference strain rate that was taken by Vöhringer [90] to be $10^{20} \mathrm{~s}^{-1}$.

The effect of work hardening can be incorporated into equation (21) by adding the term $C_{2} \epsilon^{n}$ to the thermal component of stress; in FCC metals work hardening increases the density of forest dislocations, which constitute short-term barriers. The parameters that were used for the $\mathrm{Cu}-\mathrm{Zn}$ are given in Table 4 .

The results of calculations are represented in the slip-twinning transition plots of Fig. 10, in which equations (20) and (21) were used. These calculations were carried out for different $\mathrm{Cu}-\mathrm{Zn}$ alloys: 5, 10,
Table 4. Slip and twinning parameters for $\mathrm{Cu}-\mathrm{Zn}$ alloys (from Vöhringer)

\begin{tabular}{ll}
\hline Slip & \\
$K_{3}(\mathrm{MPa})$ & 96 \\
$K_{4}(\mathrm{MPa})$ & 300 \\
$\dot{\epsilon}_{0}\left(\mathrm{~s}^{-1}\right)$ & $10^{20}$ \\
$\epsilon_{\mathrm{L}}$ & 0.98 \\
$p$ & $3 / 2$ \\
$q$ & $1 / 2$ \\
$k_{\mathrm{s}}\left(\mathrm{MPa} \mathrm{mm} \mathrm{m}^{1 / 2}\right)$ & 8.2 \\
$\Delta \Phi_{0}(\mathrm{~J})$ & $2.56 \times 10^{-19}$ \\
$T$ winning & \\
$K_{1}(\mathrm{MPa})$ & 12.5 \\
$K_{2}(\mathrm{MPa})$ & 6000 \\
$\gamma_{\mathrm{Cu}}\left(\mathrm{mJ} / \mathrm{m}^{2}\right)$ & $57 \pm 8$ \\
$G(\mathrm{GPa})$ & 43 \\
$b(\mathrm{~nm})$ & 0.3 \\
$k_{\mathrm{T}}\left(\mathrm{MPa} \mathrm{mm} \mathrm{mm}^{1 / 2}\right)$ & 16 \\
\hline
\end{tabular}

(a)

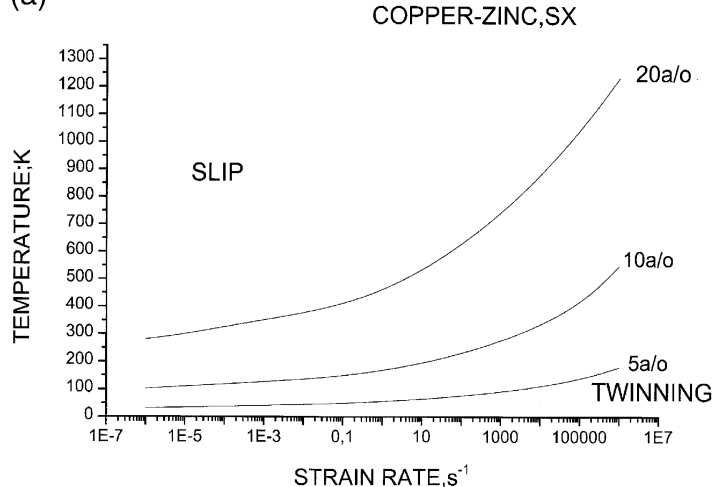

(b)

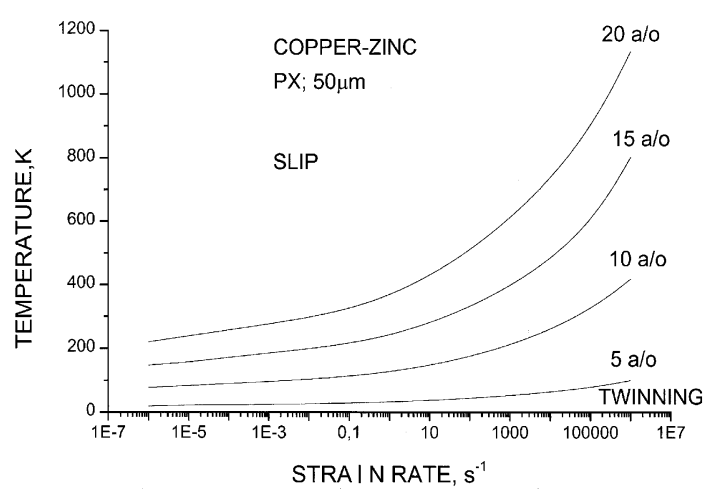

Fig. 10. Calculated slip-twinning transition for $\mathrm{Cu}-\mathrm{Zn}$ brasses: (a) monocrystal; (b) polycrystal with grain size $50 \mu \mathrm{m}$

15 , and $20 \%$ at $\mathrm{Zn}$. Figure 10(a) shows the results for monocrystalline brass, while Fig. 10(b) shows the results for a polycrystalline brass with a grain size of $50 \mu \mathrm{m}$. It is clear that the addition of $\mathrm{Zn}$ increases the propensity for twinning, displacing the slip-twinning transition upwards. By using equation (21) with the added term $C_{2} \epsilon^{n}$, it is possible to establish the onset of twinning after different amounts of plastic deformation. Since $\mathrm{Cu}-\mathrm{Zn}$ is $\mathrm{FCC}$, twinning can occur after significant plastic deformation. 


\section{ANALYTICAL PREDICTION OF THE CRITICAL NUCLEUS SIZE}

In this section, an expression for the twin-stress dependence on SFE will be derived using the classical nucleation theory. It is recognized that this approach has a number of simplifying assumptions and that the complex dislocation interactions involved in twinning are not incorporated. The induced stress acting on the barrier will generate an elastic distortion, which has to supply the energy required to create a twin-matrix interface $\left(\gamma_{\mathrm{TB}}\right)$, and the energy needed for the formation of the twin as an Eshelby's inclusion $(\Delta W)$. The total change in free energy can thus be written as

$$
\Delta \Phi=\Delta W+\gamma_{\mathrm{TB}} A .
$$

The interface area of the twin embryo is denoted by $A$. In the case when the embryo is an oblate spheroid $\left(a_{1}=a_{2}=r, a_{3}<r\right)$, we have (Fig. 11)

$$
A=\pi r^{2}\left(2+\frac{\rho^{2}}{\sqrt{1-\rho^{2}}} \ln \frac{1+\sqrt{1-\rho^{2}}}{1-\sqrt{1-\rho^{2}}}\right),
$$

where

$$
\rho=\frac{a_{3}}{r}<1
$$

If $\rho \ll 1$, then with a good accuracy

$$
A \approx 2 \pi r^{2} \text {. }
$$

Suppose that, under applied shear stress $\sigma_{13}^{0}$, the twinning plane is the plane $\left(x_{1}, x_{2}\right)$, whose normal is in the direction $x_{3}$, and that the twin embryo has undergone a plastic shear $\epsilon_{13}^{\mathrm{p}}$ in the direction parallel to $x_{1}$. Furthermore, suppose that the shear modulus of the parent material is $G$, while the shear modulus of the embryo (due to its possible crystalline reorientation relative to the surrounding matrix) is $G^{*}$. The

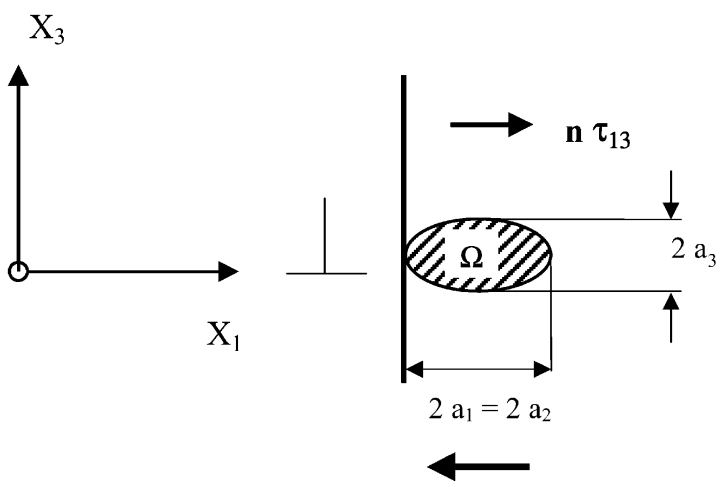

Fig. 11. Dislocation pile-up and ellipsoidal (oblate spheroid) twin embryo. stress state within the ellipsoidal twin can then be determined from the Eshelby's [91, 92] solution for an ellipsoidal inhomogeneity in an infinite matrix under applied stress $\sigma_{13}^{0}$. This is

$$
\sigma_{13}=2 G\left(2 S_{1313}-1\right) \epsilon_{13}^{* *}
$$

where

$$
\epsilon_{13}^{* *}=\epsilon_{13}^{\mathrm{p}}+\epsilon_{13}^{*}=\frac{\left(G-G^{*}\right) \epsilon_{13}^{0}+G^{*} \epsilon_{13}^{\mathrm{p}}}{2\left(G^{*}-G\right) S_{1313}+G} .
$$

The homogenization eigenstrain is denoted by $\epsilon_{13}^{*}$, and $\epsilon_{13}^{0}=\sigma_{13}^{0} / 2 G$. The component of the Eshelby's tensor $S_{1313}$ for the oblate spheroid is

$$
S_{1313}=\frac{1}{2}\left(1-\frac{2-v}{1-v} \frac{\pi \rho}{4}\right)
$$

where $v$ is the Poisson ratio of the matrix material.

The change in the elastic potential energy of the matrix induced by the creation of the twin embryo is (e.g. Mura [93])

$$
\begin{gathered}
\Delta W=-\frac{1}{2} \int_{V} \sigma_{i j}^{0} \epsilon_{i j}^{*} \mathrm{~d} V-\frac{1}{2} \int_{V} \sigma_{i j} \epsilon_{i j}^{\mathrm{p}} \mathrm{d} V \\
-\int_{V} \sigma_{i j}^{0} \epsilon_{i j}^{\mathrm{p}} \mathrm{d} V,
\end{gathered}
$$

where

$$
V=\frac{4 \pi}{3} \rho r^{3}
$$

is the volume of the embryo. For uniform plastic strain $\epsilon_{13}^{\mathrm{p}}$ and uniform driving stress $\sigma_{13}^{0}$, equation (29) becomes

$$
\Delta W=-\left[\sigma_{13}^{0} \epsilon_{13}^{* *}+\left(\sigma_{13}^{0}+\sigma_{13}\right) \epsilon_{13}^{\mathrm{p}}\right] \frac{4 \pi}{3} \rho r^{3} .
$$

Upon the substitution of equations (26)-(28) into equation (31), there follows

$$
\Delta W=-\left(\varphi \sigma_{13}^{0}-\frac{2-v}{1-v} \frac{\pi \rho}{2} G \epsilon_{13}^{\mathrm{p}} \epsilon_{13}^{* *}\right) \frac{4 \pi}{3} \rho r^{3},
$$

where

$$
\varphi=\frac{2 \epsilon_{13}^{\mathrm{p}}-\left(1-\frac{G}{G^{*}}\right)\left(\frac{\sigma_{13}^{0}}{2 G}+\frac{2-v}{1-v} \frac{\pi \rho}{4} \epsilon_{13}^{\mathrm{p}}\right)}{1-\left(1-\frac{G}{G^{*}}\right) \frac{2-v}{1-v} \frac{\pi \rho}{4}} .
$$


The corresponding change of the total free energy is

$$
\begin{aligned}
\Delta \Phi=-\left(\varphi \sigma_{13}^{0}\right. & \left.-\frac{2-v}{1-v} \frac{\pi \rho}{2} G \epsilon_{13}^{\mathrm{P}} \epsilon_{13}^{* * *}\right) \frac{4 \pi}{3} \rho r^{3} \\
& +2 \pi r^{2} \gamma_{\mathrm{TB}} .
\end{aligned}
$$

To determine the relationship between the critical size of the twin embryo and the required nucleation stress $\sigma_{13}^{0}$, we require that

$$
\frac{\partial(\Delta \Phi)}{\partial \rho}=0, \frac{\partial^{2}(\Delta \Phi)}{\partial \rho^{2}}>0,
$$

and

$$
\frac{\partial(\Delta \Phi)}{\partial r}=0, \frac{\partial^{2}(\Delta \Phi)}{\partial r^{2}}<0 .
$$

These conditions define the coordinates of a saddle point of the surface $\Delta \Phi(\rho, r)$, as in the analysis used by Yoo and Lee [94], and Lebensohn and Tomé [71]. Physically, this implies that once twin is formed, it grows in an unstable manner with respect to the increase in $r$, but with a constant aspect ratio $\rho$ (selfsimilar twin growth, with $a_{3}$ increasing in proportion to $r$ ).

Simple results are obtained if the twin's crystalline reorientation is neglected, so that

$$
G^{*}=G, \epsilon_{13}^{*}=0, \epsilon_{13}^{* *}=\epsilon_{13}^{\mathrm{p}}, \varphi=2 \epsilon_{13}^{\mathrm{p}},
$$

and

$$
\begin{aligned}
\Delta \Phi=-\left(2 \sigma_{13}^{0}\right. & \left.-\frac{2-v}{1-v} \frac{\pi \rho}{2} G \epsilon_{13}^{\mathrm{p}}\right) \epsilon_{13}^{\mathrm{p}} \frac{4 \pi}{3} \rho r^{3} \\
& +2 \pi r^{2} \gamma_{\mathrm{TB}} .
\end{aligned}
$$

This approximation is particularly satisfactory if the plastic strain $\epsilon_{13}^{\mathrm{P}}$ is significantly more pronounced than the strain $\epsilon_{13}^{0}$, which will be the case in our numerical evaluations. The condition (35) then becomes

$$
\rho_{\mathrm{c}}=\frac{1-v}{2-v} \frac{2}{\pi} \frac{\sigma_{13}^{0}}{G \epsilon_{13}^{\mathrm{p}}}
$$

while condition (36) gives

$$
r_{\mathrm{c}}=\frac{\gamma_{\mathrm{TB}}}{\left(2 \sigma_{13}^{0}-\frac{2-v}{1-v} \frac{\pi \rho_{\mathrm{c}}}{2} G \epsilon_{13}^{\mathrm{p}}\right) \rho_{c} \epsilon_{13}^{\mathrm{p}}} .
$$

Upon substitution of equation (39) into equation (40), there follows

$$
r_{\mathrm{c}}=\frac{\pi}{2} \frac{2-v}{1-v} \frac{G \gamma_{\mathrm{TB}}}{\left(\sigma_{13}^{0}\right)^{2}} .
$$

For example, if $v=1 / 3$, we have

$$
\rho_{\mathrm{c}}=\frac{4}{5 \pi} \frac{\sigma_{13}^{0}}{G \epsilon_{13}^{\mathrm{p}}}
$$

and

$$
r_{\mathrm{c}}=\frac{5 \pi}{4} \frac{G \gamma_{\mathrm{TB}}}{\left(\sigma_{13}^{0}\right)^{2}} .
$$

An expression for $\rho_{\mathrm{c}}$ similar to that given by equation (42) was originally derived for FCC metals by Venables [41]. A generalization to anisotropic elasticity was made by Lebensohn and Tomé [71].

For the driving stress of twin formation $\sigma_{13}^{0}$ we shall take the stress at the tip of the pile-up at the grain boundary of the neighboring grain. The representative value for copper is about $1 \mathrm{GPa}$. Since the twinning shear strain of copper is about $\epsilon_{13}^{p}=0.354$, and $G=48.3 \mathrm{GPa}$, we obtain from equation (42) the critical aspect ratio

$$
\rho_{\mathrm{c}}=0.015 \text {. }
$$

It should be noted that the twinning shear strain is rather large, which puts some restrictions on the applicability of the analysis based on classical Eshelby's inclusion theory, used in this and most of the previous work on the subject.

The twin-boundary energy can be considered to be the sum of the coherent twin-boundary energy $\left(\gamma_{\mathrm{CTB}}\right)$ and the energy of the twinning dislocations. The coherent twin-boundary energy is related to the stacking fault energy $\left(\gamma_{\mathrm{SF}}\right)$ by

$$
\gamma_{\mathrm{CTB}}=(0.5-0.75) \gamma_{\mathrm{SF}} .
$$

For copper, the value of $\gamma_{\mathrm{SF}}=0.055 \mathrm{~J} / \mathrm{m}^{2}$ is most commonly used, although there is a considerable variation of this estimate, and the value as high as $\gamma_{\mathrm{SF}}=0.075 \mathrm{~J} / \mathrm{m}^{2}$ has been reported. Due to uncertainties regarding the precise estimate of the total twin-boundary energy, we used three values of $\gamma_{\mathrm{TB}}$, one equal to $\gamma_{\mathrm{SF}}$, the other equal to $2 \gamma_{\mathrm{SF}}$, and the third equal to $10 \gamma_{\mathrm{SF}}$. The plot of $r_{\mathrm{c}}$ vs $\sigma_{13}^{0}$, obtained from equation (43) is shown in Fig. 12. Evidently, for $\gamma_{\text {Тв }}=0.055 \mathrm{~J} / \mathrm{m}^{2}, G=48.3 \mathrm{GPa}$ and $\sigma_{13}^{0}=1 \mathrm{GPa}$, the critical radius is 


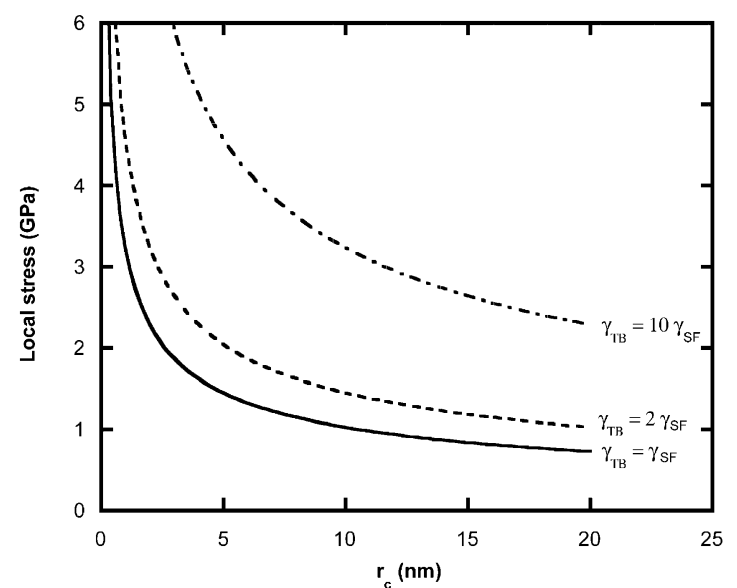

Fig. 12. Critical radius for twin embryo, $r_{\mathrm{c}}$, as a function of local stress $\sigma_{13}^{0}$. Calculations are for copper with three values of the twin-boundary energy, $\gamma_{\mathrm{GB}}=0.055,0.11$ and $0.55 \mathrm{~J} / \mathrm{m}^{2}$, and the shear modulus $G=48.3 \mathrm{GPa}$.

$$
r_{\mathrm{c}}=10.4 \mathrm{~nm} \text {. }
$$

For $\mathrm{Fe}-3.2 \mathrm{wt} \% \mathrm{Si}$ (BCC), we used $G=70 \mathrm{GPa}$, $\gamma_{\mathrm{TB}}=1 \mathrm{~J} / \mathrm{m}^{2}, \epsilon_{13}^{\mathrm{p}}=0.355$, and $\sigma_{13}^{0}=2 \mathrm{GPa}$ and calculated

$$
\rho_{\mathrm{c}}=0.02, r_{\mathrm{c}}=68.7 \mathrm{~nm}
$$

For Ti (HCP) with $G=40 \mathrm{GPa}, \gamma_{\mathrm{TB}}=0.3 \mathrm{~J} / \mathrm{m}^{2}$, $\epsilon_{13}^{\mathrm{p}}=0.2$, and $\sigma_{13}^{0}=1 \mathrm{GPa}$, we obtained

$$
\rho_{\mathrm{c}}=0.032, r_{\mathrm{c}}=47 \mathrm{~nm}
$$

\section{GRAIN-SIZE EFFECTS AND THE SIZE OF PILE- UPS}

It is simple to relate the local stress $\sigma_{13}^{0}$, driving the twin formation, and the globally applied stress $\tau_{13}=\tau$ by considering the number of dislocations at the pile-up and by using the equation developed by Eshelby et al. [95]. The shear stress $\sigma_{13}^{0}$ is created by the pile-up equivalent dislocation with the Burgers vector $n b$ and the shear stress $n \tau$ at a distance $l / 4$ from the tip of the pile-up of length $l$. The externally applied stress $\tau$ is related to the number of dislocations $n$ in the pile-up by

$$
n=\frac{\alpha \pi l \tau}{G b}
$$

where $\alpha$ is parameter that depends on the dislocation character ( $\alpha=1$ for edge dislocations). The relationship between the local stress $\sigma_{13}^{0}$ and the globally applied stress $\tau$ is thus

$$
\sigma_{13}^{0}=n \tau=\frac{\alpha \pi l \tau^{2}}{G b}
$$

If equation (43) is adopted, we have

$$
\sigma_{13}^{0}=\left(\frac{5 \pi}{4} \frac{G \gamma_{\mathrm{TB}}}{r_{\mathrm{c}}}\right)^{1 / 2} \text {. }
$$

Equating the right-hand sides of equations (50) and (51) gives an expression for the length of the pile-up required for the twinning operation

$$
l=\frac{1}{\alpha} \frac{G}{\tau^{2}}\left(\frac{5}{4 \pi} \frac{G \gamma_{\mathrm{TB}}}{r_{\mathrm{c}}}\right)^{1 / 2} b .
$$

Using the Hall-Petch relationship between the global twinning stress $\tau$ and the grain size $d$

$$
\tau=\tau_{0}+k_{\mathrm{T}} d^{-1 / 2}
$$

the substitution into equation (52) gives

$$
l=\frac{1}{\alpha} \frac{G}{\left(\tau_{0}+k_{\mathrm{T}} d^{-1 / 2}\right)^{2}}\left(\frac{5}{4 \pi} \frac{G \gamma_{\mathrm{TB}}}{r_{\mathrm{c}}}\right)^{1 / 2} b .
$$

Numerical evaluations reveal that $l$ is much smaller than the grain size. For example, for copper with $k_{\mathrm{T}}=0.30 \mathrm{MPam}^{1 / 2}, \tau_{0}=40 \mathrm{MPa}$ and $d=10^{3} \mathrm{~nm}$, we obtained $l=34 \mathrm{~nm}$, which is about 30 times smaller than the grain size $d$. For the grain size of $10^{4} \mathrm{~nm}$, the maximum length of the pile-up is about 40 times smaller than the grain size $d$. An even smaller ratio $l / d$ is found for $\mathrm{Fe}-3 \% \mathrm{Si}$. Although elastic anisotropy and nonlinear effects in the Eshelby's inclusion analysis were neglected, this strongly suggests that the size of the pile-ups responsible for the onset of twinning is much smaller than the grain size. An alternative explanation would be that other mechanisms are responsible for the stress concentrations necessary to initiate twinning.

\section{CONCLUSIONS}

An analytical treatment that describes the initiation of mechanical twinning is developed and presented in graphical form as strain rate-temperature plots. This constitutive description is applied to metals representative of these principal crystal systems: BCC (iron); FCC (copper and $\mathrm{Cu}-\mathrm{Zn}$ brass); and HCP (titanium). For BCC metals, an equation for the twinning stress is derived from the consideration of the activation of Frank-Read sources. This provides a temperature and strain-rate dependence that are compared with experimental results for iron by Harding [51, 52]. For FCC 
and HCP metals, the authors are not aware of any experimental results on the effect and the twinning stress is assumed to be constant. For brasses, the SFE dependence of the twinning stress is incorporated into the twinning equation. An important observation is that the Hall-Petch slope for twinning is consistently larger than the one for slip. This manifests itself in a considerable enhancement of the predisposition for twinning as the grain size is increased. The difference between the two slopes is not well understood.

An analysis using the Eshelby inclusion theory shows that the critical twinning stress has a SFE dependence, in accordance with experimental measurements. The analysis leads to quantitative predictions. The effects of grain size and SFE are evaluated and the results indicate that the grain-scale pileups are not the source of the stress concentrations giving rise to twinning in copper. The calculation is also carried out for $\mathrm{Fe}-3 \% \mathrm{Si}$ with similar conclusions. An immediate application of the constitutive description presented here is in the Weertman-Ashby deformation mechanism maps. As an illustration, Fig. 13 shows a map for titanium (G.S. $=100 \mu \mathrm{m})$, to which a twinning domain was added. The original map had a domain called "obstacle controlled plasticity". This domain is here divided into "twinning" and "slip" domains. The same procedure can be applied to any deformation-mechanism map, and it is suggested that this will complement the maps and enhance their usefulness.

The procedure presented herein can be used to predict the critical pressure for twinning in shock compression experiments. It is known that different metals have different threshold pressures for the initiation of twinning; it has been established by Murr [96] that for FCC metals this pressure is a function of the SFE. The analysis requires the use of the Swegle-Grady [97] equation and the procedure is delineated in Ref. [98].

Acknowledgements-The presented research was funded by the US Army Research Office through the Multidisciplinary University Research Institute (MURI), Contract No. DAAH 0496-1-0376, and by the Humboldt Foundation of Germany through a Senior Scientist Award to the first author. Mrs Q. Xue and D. Khieng were helpful in preparation of the manuscript. The assistance of Drs T. Dummer and M. Ehlers during the visit of M.A.M. to the University of Karlsruhe is appreciated. Discussions with Professors R. W. Armstrong, G. Thomas and X. Markenscoff were most helpful in the development of the concepts presented in this paper.

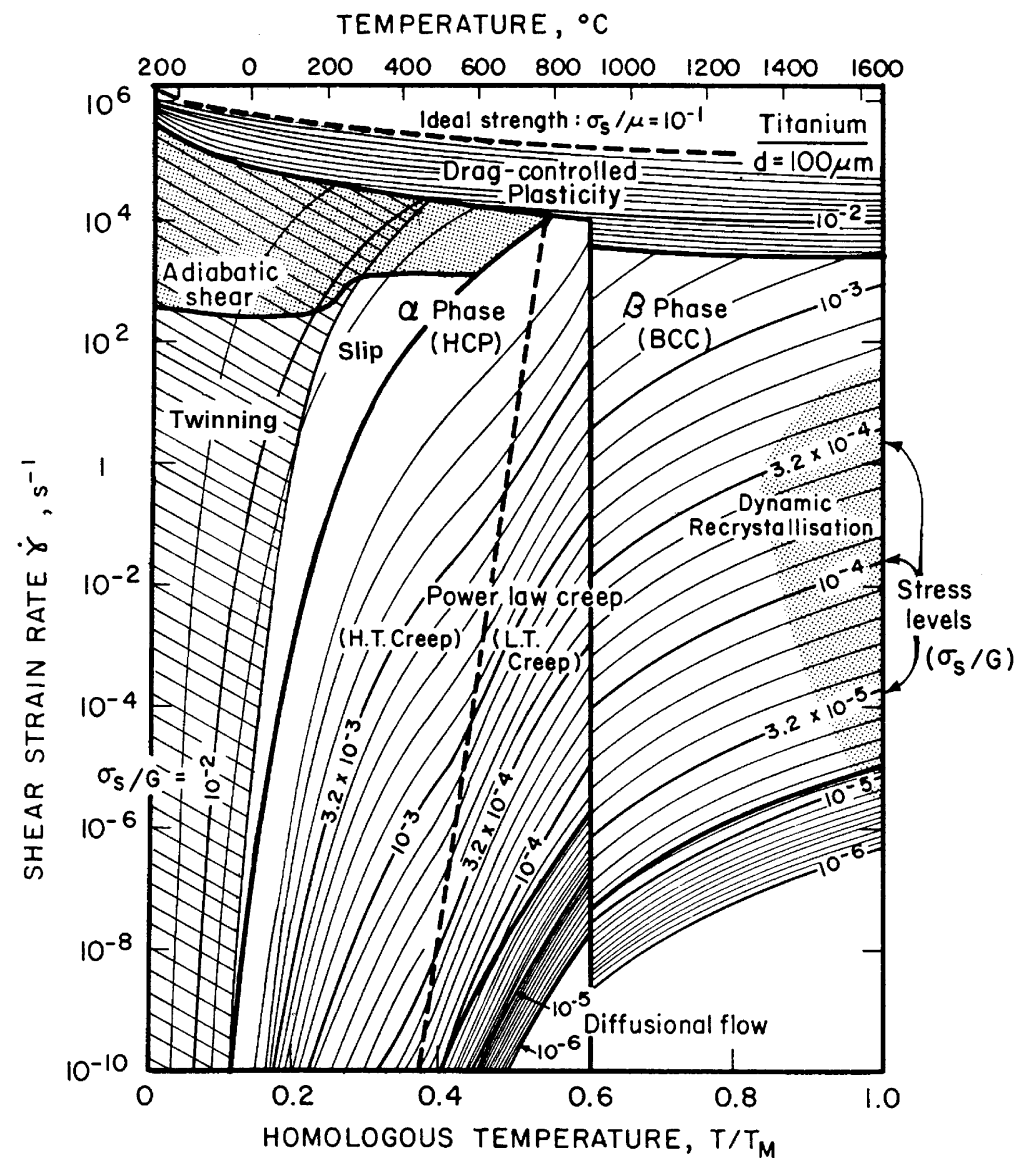

Fig. 13. Weertman-Ashby map for titanium (from Frost and Ashby [14], figure 17.4), with $d=100 \mu \mathrm{m}$, in which a twinning domain has been inserted for $0.1 \%$ Oeq. titanium. 


\section{REFERENCES}

1. Thomas, G., Private communication, 1998

2. Becker, R., Z. Phys., 1925, 26, 919.

3. Seeger, A., Z. Naturf., 1954, 9A, 758

4. Seeger, A., Z. Naturf., 1954, 9A, 818.

5. Seeger, A., Z. Naturf., 1954, 9A, 851

6. Christian, J. W. and Mahajan, S., Prog. Mater. Sci., 1995, 39, 1.

7. Hall, E. O., Twinning. Butterworths, London, 1954.

8. Klasen-Neklyudova, N. V., Mechanical Twinning of Crystals. Plenum Press, New York, 1964.

9. R. E. Reed-Hill, J. P. Hirth and H. C. Rogers, ed. Deformation Twinning,. Gordon \& Breach, New York 1964.

10. Mahajan, S. and Williams, D. F., Int. Metal. Rev., 1973, 18, 43.

11. Narita, N. and Takamura, J. -I., in Dislocations in Solids, Vol. Vol. 9, ed. F. R. N. Nabarro. Elsevier, Amsterdam, 1992, pp. 135-189.

12. Gray, G. T. III, in Encyclopedia of Materials Science and Engineering, Vol. Supplementary Vol. 2, ed. R. W. Cahn. Pergamon Press, Oxford, 1990, pp. 859-866.

13. Weertman, J., Trans. AIME, 1963, 227, 1475.

14. Frost, H. J. and Ashby, M. F., Deformation-mechanism Maps. Pergamon Press, Oxford, 1982.

15. Mulford, R. A. and Kocks, U. F., Acta metall., 1979, 27, 1125 .

16. Asgari, S., El-Danaf, E., Kalidindi, S. R. and Doherty, R. D., Metall. Trans. A, 1970, 1997, 28.

17. El-Danaf, E., Kalidindi, S. R. and Doherty, R. D., Metall. Mater. Trans., 1999, 30A, 1223.

18. Kalidindi, S. R., in Advances in Twinning, ed. S. Ankem and C. S. Pande. TMS/AIME, Warrendale, PA, 1999, p. 83.

19. Kalidindi, S. R., J. Mech. Phys. Sol., 1998, 48, 267.

20. Staroselsky, A. and Anand, L., J. Mech. Phys. Sol., 1998, 46, 671.

21. Karaman, I., Sehitiglu, H., Beaudoin, A. J., Chumlyaka, Y. I., Maier, H. J. and Tomé, C. N., Acta mater., 2000, 48, 2031.

22. Vöhringer, O., Z. Metall., 1970, 67, 518.

23. Cottrell, A. H., J. Mech. Phys. Solids, 1952, 1, 53.

24. Seeger, A., Phil. Mag., 1954, 46, 1194.

25. Ono, K., J. Appl Phys., 1968, 39, 1803.

26. Vöhringer, O. Die Strukturmechanischen Grundlagen der Plastischen Verformung von Vielkristallinen-Kupfer-Legierungen. Habilitationsschrift, Karlsruhe, 1972.

27. Kocks, U. F., Argon, A. S. and Ashby, M. F., Prog. Mater. Sci., 1975, 19, 1.

28. Zerilli, F. J. and Armstrong, R. W., J. Appl. Phys., 1987, 61, 1816.

29. Zerilli, F. J. and Armstrong, R. W., J. Appl. Phys., 1990, 68, 915.

30. Follansbee, P. S. and Kocks, U. F., Acta metall. mater. 1988, 36, 81

31. Armstrong, R. W. and Worthington, P. J., in Metallurgical Effects at High Strain Rates, ed. R. W. Rohde, B. M. Butcher, J. R. Holland and C. H. Karnes. Plenum Press, New York, 1973, pp. 401-414.

32. Zerilli, F. J. and Armstrong, R. W., J. Phys. IV, 1997, 7, C3-637.

33. Tomé, C. N. et al., Symposium on HCP Metals. TMS/AIME, New Orleans, 2001, [in press].

34. Bell, R. L. and Cahn, R. W., Proc. R. Soc., 1957, A239, 494.

35. Price, P. B., Proc. R. Soc., 1961, A260, 251.

36. Suzuki, H. and Barrett, C. S., Acta metall., 1958, 6, 156.

37. Haasen, P. and King, H., Z. Metallk., 1960, 51, 722.

38. Miura, S., Takamura, J. and Narita, N., Trans. Jap. Met., 1968, 9, S555.

39. Cohen, J. B. and Weertman, J., Acta metall., 1963, 11, 997-1368.

40. Venables, J. A., Phil. Mag., 1961, 6, 379.
41. Venables, J. A., in Deformation Twinning, ed. R. E. ReedHill, J. P. Hirth and H. C. Rogers. Gordon \& Breach, New York, 1964, pp. 77-116.

42. Sleeswik, A. W., Phil. Mag., 1963, 8, 467.

43. Mahajan, S. and Chin, G. Y., Acta metall., 1973, 21, 1353.

44. Bolling, G. F. and Richman, R. H., Acta metall., 1965, 13, 709-745.

45. Cottrell, A. H. and Bilby, B. A., Phil. Mag., 1951, 42, 573.

46. Sleeswik, A. W., Phil. Mag., 1974, 29, 407.

47. Hirth, J. P. and Rogers, H. C., in Deformation Twinning, ed. R. E. Reed-Hill, J. P. Hirth and H. C. Rogers. Gordon \& Breach, New York, 1964, p. 112.

48. Orowan, E. Dislocations in Metals, ed. M. Cohen. AIME, 1958, p. 116.

49. Koester, W. and Speidel, M. O., Z. Metallk., 1965, 9, 1150.

50. Reed-Hill, R. E., in Inhomogeneity of Plastic Deformation. ASM, Metals Park, OH, 1973, p. 285.

51. Harding, J., Mem. Sci. Rev. Met., 1968, 65, 245.

52. Harding, J., Proc. R. Soc., 1967, 299A, 464.

53. Chichili, D. R., Ramesh, K. T. and Hemker, K. J., Acta mater., 1998, 46, 1025

54. Vöhringer, O., Z. Metallk., 1976, 67, 51.

55. Nilles, J. L. and Owen, W. S., in Mechanical Behavior of Materials. The Society of Metals, Japan, 1972, p. 97.

56. Loehe, D. and Vöhringer, O., Z. Metallk., 1986, 77, 557.

57. Song, S. G. and Gray, G. T. III, Metall. Mater. Trans., 1995, 26A, 2665.

58. Thornton, P. R. and Mitchell, T. E., Phil. Mag., 1962, 7, 361.

59. Hull, D., Acta metall., 1961, 9, 191.

60. Moisev, V. F. and Trefilov, V. I., Phys. Stat. Sol., 1966, 18, 881 .

61. Marcinkowski, M. J. and Lipsitt, H. A., Acta metall., 1962, 10, 995.

62. Lindley, T. C. and Smallman, R. E., Acta metall., 1963, 11, 361 .

63. Gray, G. T. III, Kaschner, G. C., Mason, T. A., Maudlin, P. J. and Chen, S. R., in Advances in Twinning, ed. S. Ankem and C. S. Pande. TMS/AIME, Warrandale, PA, 1999 , p. 157.

64. Romhanji, E., Milenkovic, V. and Drobnjak, D., Z. Metallk., 1992, 83, 110.

65. Lahaie, D., Embury, J. D., Chadwick, M. M. and Gray III, G. T., Scripta Met., 1992, 27, 139.

66. Meyers, M. A., Andrade, U. R. and Chokshi, A. H., Metall. Mater. Trans., 1995, 26A, 2881.

67. Narita, N., Hatano, A., Takamura, J., Yoshida, M. and Sakamoto, H., J. Japan Inst. Met., 1978, 42, 533.

68. Vöhringer, O., Z. Metallk., 1974, 65, 352.

69. Serra, A. and Bacon, D. J., Phil. Mag., 1986, A54, 793.

70. Serra, A., Pond, R. C. and Bacon, D. J., Acta metall. mater., 1991, 39, 1469

71. Lebensohn, R. A. and Tomé, C. N., Phil. Mag., 1993, 67, 187.

72. Patel, J. R. and Cohen, M., Acta metall., 1953, 1, 531.

73. Thadhani, N. N. and Meyers, M. A., Prog. Mater. Sci., 1986, 30, 1.

74. Koester, W. and Speidel, M. O., Z. Metallk., 1965, 56, 585.

75. Okazaki, K. and Conrad, H., Acta metall., 1973, 21, 1117.

76. Ogawa, K. and Maddin, R., Acta metall., 1964, 12, 7131203.

77. Gilman, J. J., Phil. Mag., 1997, 76, 329.

78. Johnston, W. G. and Gilman, J. J., J. Appl. Phys., 1959, 30, 129.

79. Stein, D. F. and Low, J. R. Jr, J. Appl. Phys., 1960, 31, 362.

80. Jassby, K. M. and Vreeland, T. Jr, Phil. Mag., 1970, 21, 1147.

81. Greeman, W. F., Vreeland, T. Jr and Wood, D. S., J. Appl. Phys., 1967, 89, 3595.

82. Kleintges, M. and Haasen, P., Scripta Met., 1980, 14, 999.

83. Suzuki, T. and Ishii, T., Trans. Jap. Inst., 1968, 9, 687.

84. Zerilli, F. J. and Armstrong, R. W., in Shock Compression 
of Condensed Matter, ed. S. C. Schmidt and W. C. Tao. AIP, Woodbury, 1995, pp. 315-318.

85. Zerilli, F. J. and Armstrong, R. W., in MRS Symposium Proceedings, Vol. Vol. 362, ed. M. A. Otooni, R. W. Armstrong, N. J. Grant and K. Ishizaki. MRS, Pittsburgh, PA, 1995, pp. 149-154.

86. Gray III, G. T., J. Phys. IV, 1997, 7, C3-423.

87. Conrad, H., Doner, M. and de Meester, B., in Titanium Science and Technology, ed. R. I. Jaffee and H. M. Burte. Plenum Press, New York, 1973, p. 969.

88. Okazaki, K. and Conrad, H., Acta metall., 1973, 21, 1117.

89. Gallagher, P. C. J., Metall. Trans., 1970, 1, 2429.

90. Vöhringer, O., Metall., 1972, 11, 1119.

91. Eshelby, J. D., Proc. R. Soc., 1957, A241, 376.
92. Eshelby, J. D., Proc. R. Soc., 1959, A252, 561.

93. Mura, T., Micromechanics of Solids. Martinus Nijhoff, The Hague, 1982.

94. Yoo, M. H. and Lee, J. K., Phil. Mag., 1991, 63, 987.

95. Eshelby, J. D., Frank, F. C. and Nabarro, F. R. N., Phil. Mag., 1951, 42, 531

96. Murr, L. E., in Shock Waves in Condensed Matter, ed. S. C. Schmidt and N. C. Holmes. Elsevier, Amsterdam, 1988, pp. 315-320.

97. Swegle, J. W. and Grady, D. E., J. Appl. Phys., 1985, 58, 692.

98. Meyers, M. A., Vöhringer, O. and Chen, Y. J., in Advances in Twinning, ed. S. Ankem and C. S. Pande. TMS/AIME, Warrendale, PA, 1999, pp. 43-65. 